\title{
Exploring the Use of Student-Developed Outreach Videos to Provide Mental Health Wellness Education-A Pilot Project
}

\author{
Kristin Reid ${ }^{1}$, Nancy Armstrong ${ }^{1} \&$ Dana Todd $^{1}$ \\ ${ }^{1}$ Murray State University, Murray, KY, USA \\ Correspondence: Kristin Reid, Assistant Professor, School of Nursing and Health Professions, Murray State \\ University, Murray, KY, USA. Tel: 1-270-809-6670. E-mail: kreid3@ murraystate.edu
}

Received: September 22, 2021

Accepted: October 22, 2021

Online Published: October 26, 2021

doi:10.20849/ijsn.v6i4.925

URL: https://doi.org/10.20849/ijsn.v6i4.925

\begin{abstract}
BACKGROUND: Mental health and wellness outreach has been an area of concern at colleges and universities in the United States and a variety of electronic methods have been used to successfully promote health and wellness. This pilot project was in response to a previous descriptive study examining mental health issues on campus. AIMS: The primary aim of this project was to determine if implementing a peer-led outreach program in the form of bi-weekly, short-form educational videos would increase knowledge of mental health and wellness in students developing the videos. The secondary aim was to provide students an alternate clinical assignment that improved presentation development and group dynamics. METHODS: Nursing students enrolled in a psychiatric nursing course collaborated in small groups to create bi-weekly videos on topics related to mental health and wellness. RESULTS: The peer-led outreach intervention demonstrated positive outcomes, such as increased understanding of the common mental health issues facing college students and awareness of campus, as well as outside resources to assist with mental health and wellness. CONCLUSION: This project may increase the body of knowledge related to the importance of campus outreach, peer support, and general awareness of mental wellness and resources during pandemic restraints. Utilizing condensed, peer-led educational outreach via video format has the potential to aid in the educational development of psychiatric nursing students.
\end{abstract}

Keywords: undergraduate nursing students, mental wellness outreach education, health and wellness

\section{Introduction}

The COVID-19 pandemic has increased mental and emotional strain among young adults. Fruehwirth et al. (2021) compared pre-pandemic anxiety and depression rates of first-time freshmen at one university in the United States with those occurring several months into the pandemic. The percentage of students reporting their anxiety levels as moderate to severe rose from $18.1 \%$ to $25.3 \%$.

Copeland et al. (2021) surveyed 675 first-time freshmen about the impact of the COVID-19 pandemic on student emotional and behavioral functioning. A modest increase in both externalizing behaviors and attention issues in the students post-pandemic were noted. However, the researchers found that students who were enrolled in a wellness program at the university were less likely to have issues with decreased attention span or internalizing behaviors. The increase in major outside stressors in recent years is compounding the already-present climb in serious mental health outcomes in young adults. This supports the elevated focus on ensuring that college students have access to mental health and wellness resources at their colleges or universities.

In spring 2020, just prior to recognition of the developing global COVID19 pandemic and ensuing societal changes, a survey was completed at a university in the southeastern United States (Reid et al., 2021). The purpose of the survey was to query students about their perceptions of their own mental health and, more broadly, the perceived mental health concerns on campus, as well as the availability of campus resources for mental health needs. The top mental health concerns for students were perceived stress $(77.80 \%, \mathrm{n}=424)$, anxiety $(76.70 \%, \mathrm{n}=$ $418)$, depression $(65.87 \%, \mathrm{n}=359)$ and financial concerns $(42.02 \%, \mathrm{n} 229)$. A significant number of students reported that mental health strains reduced their productivity as a student, as well as in outside activities. Unfortunately, the most commonly reported coping mechanism was "holding things in" $(55.69 \%, \mathrm{n}=274)$. Additionally, around $40 \%$ of the students reported that they were unlikely to seek help if they developed a mental health concern. 
The students participating in the survey were asked to choose from a diverse list of topics related to emotional and mental health areas in which they would like to receive more information (Reid et al., 2021). The top five topics included: managing stress; coping strategies for mental and emotional health; balance work, life, and school; understanding depression, stress, and anxiety; and balancing finances. These items coincide with common causes of anxiety and mental health concerns with college students. Adams, Meyers, and Bedias (2016) found that financial strain, stress levels, and poor social skills were correlated with college student anxiety and depression. Based on the results of this survey, as well as general information about the mental and emotional health of college students, the project leaders sought to develop a pilot project to increase mental wellness outreach to the students at this university.

The Covid-19 pandemic not only affected college students from a mental health and wellness standpoint, it limited opportunities for undergraduate students in mental health-focused nursing courses' ability to work directly with patients needing psychiatric care and mental health assistance. Many nursing programs had to scramble to find ways for students to learn about mental health issues and learn how to perform mental health outreach from a distance (Fogg et al., 2020; Leigh et al., 2020). The project leaders decided to utilize undergraduate nursing students in implementing the outreach program with a focus on destigmatizing common mental health wellness issues affecting college students and to provide resources for further information for students with needs. Therefore, the nursing students would have a safe learning opportunity during the pandemic, while serving the educational needs of the greater college population.

\section{Aims}

The primary aim of this project was to determine if implementing a peer-led outreach program in the form of bi-weekly, short-form educational videos would increase knowledge of mental health and wellness in students developing the videos. The secondary aim was to provide students an alternate clinical assignment that improved presentation development and group dynamics. The video development allowed students the opportunity to create a professional video presentation that provided outreach to a select college student population.

\section{Review of Literature}

College students may have concerns about accessing mental health resources when they need them. Kim, Yu, \& Kim, 2019 surveyed 200 college students in Korea about mental health literacy and their willingness to seek mental health assistance, as needed. The researchers found that mental health literacy had a direct effect on the students' attitudes toward seeking mental health assistance. Mental health literacy had an indirect effect on the students' fear of a possible stigma in seeking mental health assistance. There appears to be a correlation between knowledge about mental health disorders and of mental health resources, and a willingness to seek assistance when appropriate. This project emphasizes the need to increase awareness of mental health and wellness issues, as well as how to access mental health resources on college campuses.

Sebastian and Richards (2017) studied the effectiveness of using informational videos about Anorexia Nervosa (AN) in increasing understanding of the disorder and reducing the stigma that may be applied to individuals with the disorder. The videos involved either a student actor or an embodied conversational agent, which is a realistic cartoon performance, portraying real-to-life experiences of a person with AN in short-from video clips. The videos helped students to better recognize the disorder. It also decreased some forms of stigma related to AN. This demonstrates that informational videos in short formats, involving relatable peers, can be effective in increasing knowledge and understanding of mental health issues.

Mass emails and social media engagement can be used as tools to promote healthy lifestyles in college students. Eifert et al. (2017) developed a program to improve the health of students on one college campus through the, "Healthy Owls Challenge." The plan was focused on both mental and physical health, with students taking photographs of themselves demonstrating healthy behaviors, using the hashtag \#HealthyOwlsChallenge throughout the year, in response to random challenges emailed to the students. They hoped the challenges would cause students to actively think about healthy behaviors and model those behaviors, as they see peers acting out these behaviors. The hashtag was used by students and student groups to promote health, but it is unclear how successful the program was in creating behavioral changes.

Simple, short-form electronic messaging has been found to be an effective tool for mental health outreach with health education reminders and support. Agyapong et al.(2017) found that twice daily supportive text messages over a three month period resulted in significantly lower depression scale scores compared to a control group, which received the text messages once every two weeks. During the COVID-19 pandemic Agyapong et al.(2021) developed a text messaging program called Text4Hope that sent daily encouraging text messages to Canadians who signed up for the service. The service resulted in significant decreases in anxiety, stress and depression. 
Gusmão et al. (2019) found that text messages geared toward promoting behavioral changes in obese patients in an effort to encourage safe weight loss resulted in significant reductions in body mass index after a four-month period.

Colorado State University worked with an outside technology company to develop a mobile device application, or app, to help students access information about various campus resources, including information about mental health and general wellness (McKenzie, 2018). The app, called You@CSU, allows access to vetted resources on topics such as mindfulness, resilience, and stress management in the form of videos, fact sheets, and talk spaces. The app appears to be successful as almost a quarter of students on the campus have registered accounts. Ninety-eight percent of users stated that they learned a new resource or skill from the app. Improved stress management was reported by $76 \%$ of the app's users. Eight-seven percent of app users reported that they had discovered a previously unknown campus resource through app usage.

It appears that a variety of electronic methods have been used to successfully promote health and wellness. However, college students may need to be more aware of the available resources for managing these issues. The College Marketing Group (How to get, 2020) recommends that mental health promotion come in the form of social media outreach, the creation of videos that normalize mental health struggles, and the utilization of student ambassadors in promoting mental health on campus. These concepts were incorporated in the project leaders' plan to promote mental health and wellness at one university campus.

Lastly, Almagro, et al. (2021) evaluated the experience of creating a video teaching activity with psychiatric nursing students in a cross-sectional descriptive study. Students were asked to volunteer to create videos on various topics and present to peers as a means to increase awareness of mental health and decrease stigma. The results were insightful and positive demonstrating that this type of teaching modality could be very effective for this population.

Overall the use of various electronic methods to engage students has been a useful tool (Almagro et al., 2021; How to get, 2020; McKenzie, 2018). Other organizations have found mental health outreach by electronic methods to be positive and timely (Agyapong et al., 2017; Eifert et al., 2017; McKenzie, 2018). Gaps identified were the combination of using media as means of mental wellness outreach and student engagement simultaneously. Facilitating outreach during challenging circumstances could be a useful tool for undergraduate nursing students to participate. Another possible weakness found in the review of literature was that most of the mental health interventions used in the research involved the use of a professionally created electronic device application, or similar items, that could be expensive to purchase and maintain. It would also take time for an institution to vet those resources, since they provide direct intervention to students. Meanwhile, there are generally campus resources focused on mental health and wellness available to students through other formats that the students could use, they just need to be made aware of them and be encouraged to take advantage of those resources. The project developers sought to assist students in finding electronic resources and on-campus resources that were already generally available and evaluated, without a great deal of additional expense to the university. Rather, the videos were used to direct students to available resources and normalize their use, through student-created videos, for those in need of mental health assistance.

\section{Methods}

\subsection{Ethical Considerations}

The project was reviewed by the institutional review board (IRB) and deemed exempt from IRB oversight. The project was implemented in August 2020 and was completed December 2020.

\subsection{Sample and Setting}

This pilot project focused on a peer-led outreach program consisting of the nursing students enrolled in a psychiatric mental health nursing course. The students developed the educational videos and were asked to evaluate the video outreach program and provide feedback. The outreach program activity was offered to all 25 students participating in the course. The average age was 22.4 years with 22 females, 3 males in the class. There were 21 out of the 25 senior nursing students completing the outreach program evaluation questionnaire, with an $84 \%$ response rate.

\subsection{Planning of Intervention}

First semester senior nursing students enrolled in a psychiatric mental health nursing course collaborated in small groups to create bi-weekly videos on topics related to mental health wellness. The video topics selected were based on a campus wide survey that assessed college students' perceptions of mental health perceptions and resources. Results revealed that students wanted more information on topics such as self-care, resiliency, mindfulness, 
budgeting, exercise and nutrition. There were a total of seven videos that were designed by groups of 4-5 students. Objectives for creating each video were based on the American Psychiatric Nursing Association Undergraduate Toolkit (Appendix A). Each content outline and video were reviewed by the lead faculty member for appropriateness, resource vetting, and effectiveness of presentation prior to dissemination.

The short-form videos (limited to three minutes or less) discussed common mental health or wellness issues that college students might face along with campus and outside resources available for college students to access for further assistance. After the video was developed and reviewed by faculty, it was then sent to all of the undergraduate nursing students via email for review.

\subsection{Methods of Evaluation}

For the evaluation of the outreach process, a six-question survey was distributed to the senior nursing students that developed the videos (Appendix B). This survey was completed using a pen and paper format with no student identifiers. The surveys were turned in at a location out of the direct sight of the project investigator, with the forms facing down on a table. The survey was offered to all of the students involved in video creation at the end of the semester, once all of the videos were completed and dispersed. The students were assured that the surveys were for program evaluation purposes, and that the surveys were anonymous and confidential, with no relationship to course grade. There were no incentives for completion of the program evaluation survey. For all survey questions a Likert-type scale was used ranging from 1-"Not helpful" to 5-"Very helpful." The survey was developed by the team and the last two questions were open ended for student suggestions.

\section{Results}

\subsection{Sample Characteristics}

There were 21 students that completed the post information via the anonymous survey. The findings revealed that 85.7\% $(\mathrm{n}=18)$ of the students believed that the video presentation improved their knowledge on the mental health topic that was presented. Two students $(11 \%)$ reported the video presentation experience as neutral in improving their knowledge on the mental health topic and only one student (3.3\%) reported it not helpful. Additional findings revealed that $85.7 \%(\mathrm{n}=18)$ of the students reported that the presentation experience improved their ability to work well with others. Only 3 students (3.3\%) reported that the presentation experience was neutral in improving the ability to work well with others. Furthermore, 16 students (76.2\%) of students found the video presentation to improve their ability to develop a presentation, while 4 students $(27.8 \%)$ rated the experience as neutral. Finally, 18 students $(85.7 \%)$ reported that the video presentation was helpful in sharing campus and other mental health resources. Only one student (3.3\%) reported the video presentation was not helpful in sharing campus and other mental health resources with two students (11\%) reporting neutral helpfulness.

Through the use of open-ended questions, students were encouraged to provide feedback about the video presentation experience. The responses were overall positive. The feedback suggested that the videos be disseminated to campus groups to expand the outreach or to display the videos on the school of nursing social media page to gain more exposure. Other suggestions included providing a formal professional presentation development tutorial prior to beginning the project. Two responses reported difficulty viewing the videos. 
Q1. Presentation Improved Knowledge of Topic Presented

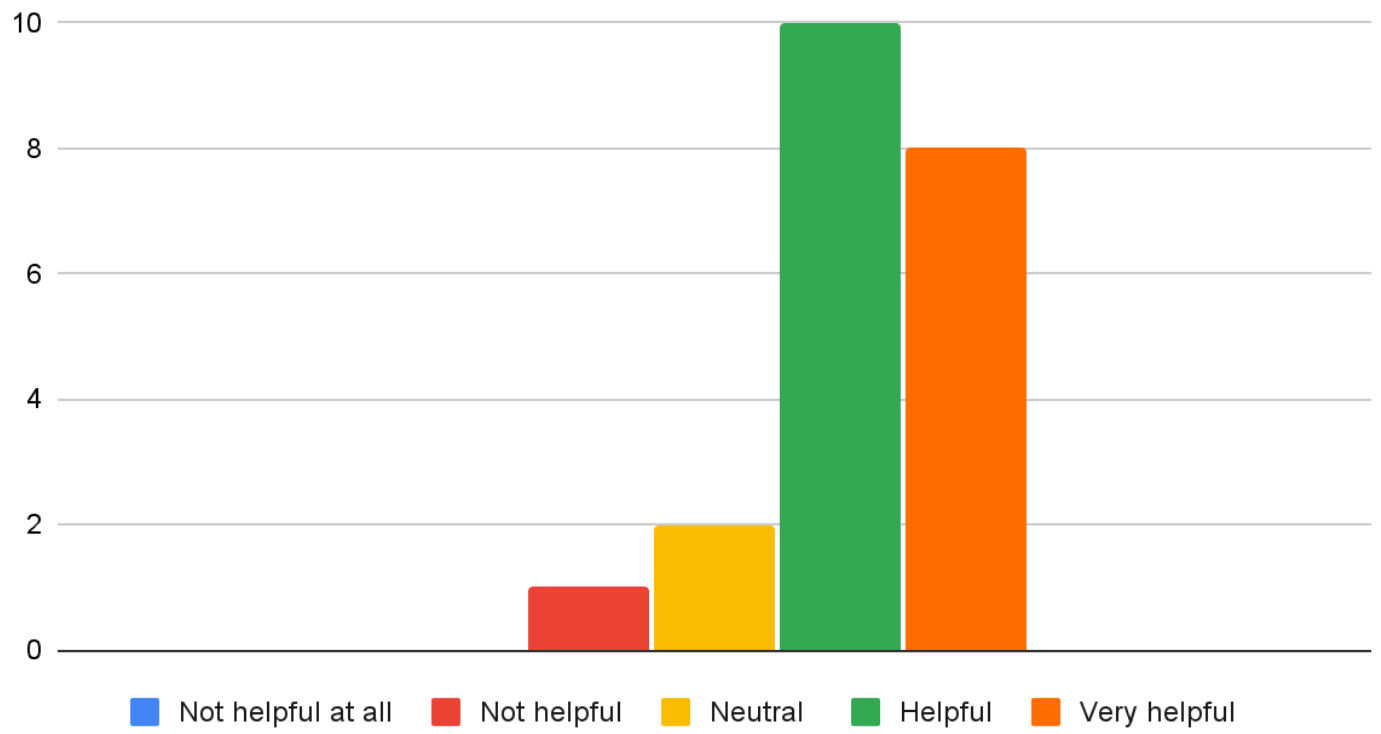

Figure 1. Responses to the topic presented

Q2. Presentation Improved Group Work Skills

20

15

10

5

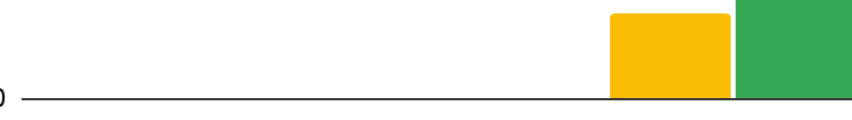

Not helpful at all Not helpful $\square$ Neutral

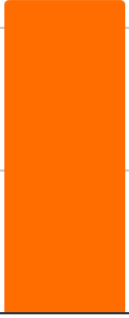

Helpful Very helpful

Figure 2. Group work skills helpfulness 


\section{Q3. Self Reported Improvement of Ability to Develop a Professional Presentation}

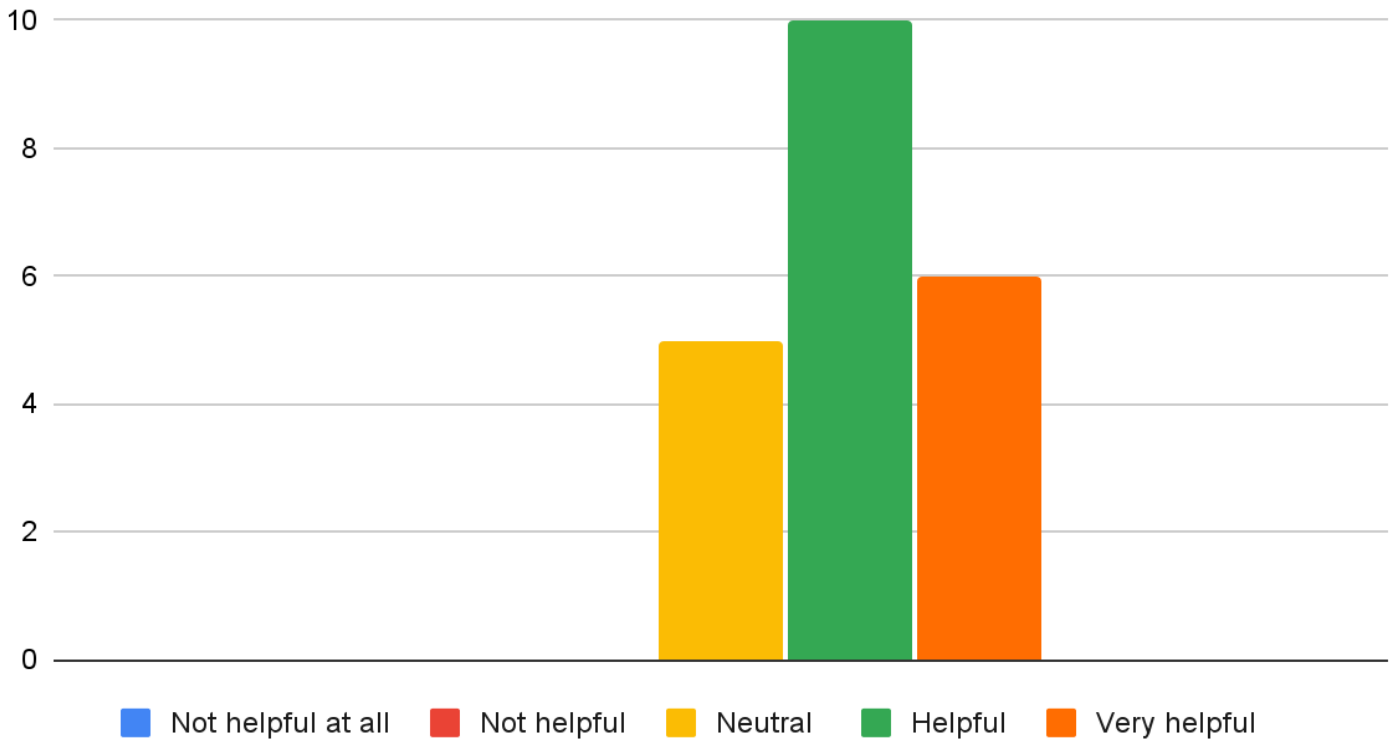

Figure 3. Professional presentation response

\section{Q4. Video Presentation Helpful with Sharing Campus and Other Mental Health Resources}

15

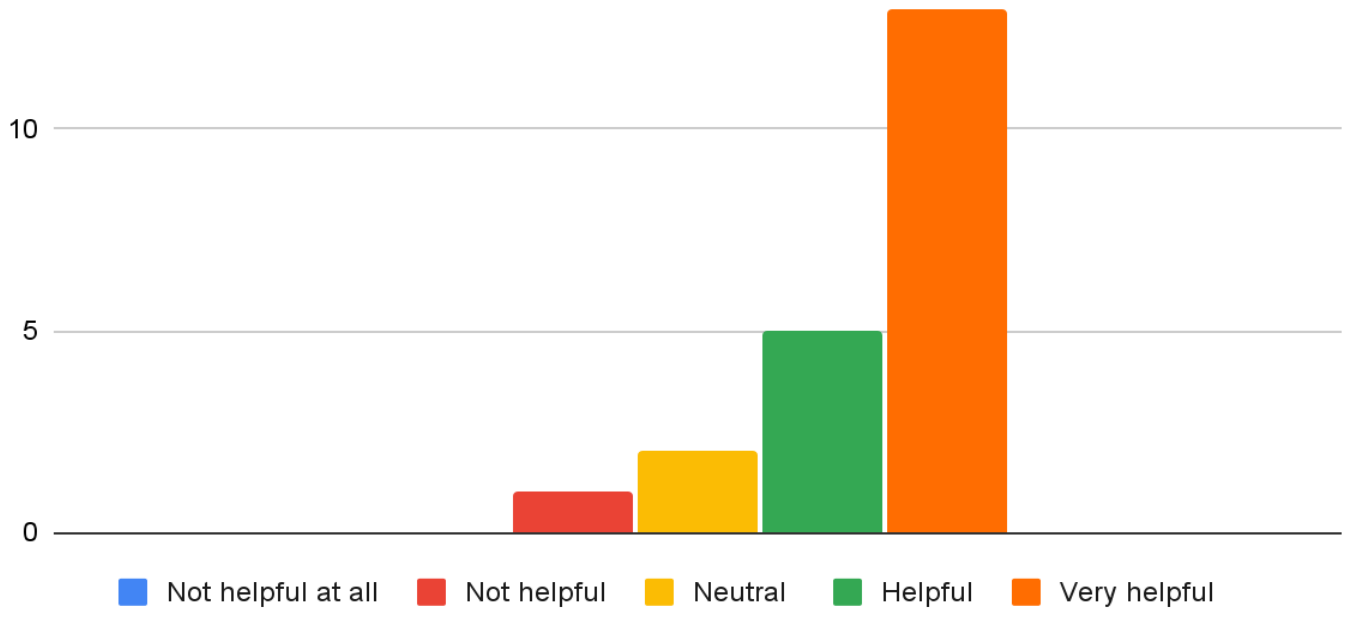

Figure 4. Helpfulness with sharing resources

\section{Discussion}

This peer-led outreach program demonstrated positive outcomes. The findings revealed that the video presentations did improve the majority of student's knowledge regarding their assigned mental health topic, improved group work skills, improved professional presentation development skills, and was a helpful tool to share campus and other mental health resources to college students. Additionally, the video outreach program was a successful alternative to a traditional psychiatric mental health clinical.

For students enrolled in this psychiatric mental health course, this project provided a broader lens to view mental wellness and outreach not only from afar, but within their community. Furthermore, students were aware of the 
potential impact that the video presentations could make on the campus by providing valuable mental health information and resource information. The project provides the students with the opportunity to see that it is important to not only make mental health resources available, but to also make it safe for students to access these resources without stigma.

The project does increase the body of knowledge related to the importance of campus outreach, peer support, and awareness of mental wellness during pandemic restraints. This video outreach program was an effective clinical activity that combined health promotion with mental health concepts. The video development and implementation was developed and implemented even among COVID-19 restrictions.

The team would recommend the future utilization of a tool that has been evaluated for validity and reliably that would aid with the assessment of this project and the outcomes. At the time of project implementation, there was not a tool that would best evaluate this project or the specific population. A reliable, validated tool would be helpful in better evaluating the results. At the time of this article, the project leaders have plans to expand the project and evaluate effectiveness on a larger scale.

\subsection{Limitations}

There are several limitations of this project. The number of students participating in the video outreach program was small. Incorporating the video outreach program with a larger number of student participants would be helpful to verify the information. Additional limitations include the difficulty with accessing the videos that some of the students reported. There are multiple factors that could contribute to the difficulty of accessing the videos and it is impossible to control for all of those variables. Finally, the lack of a validated evaluation tool for the project evaluation is a limitation of this project. This video outreach program is to be replicated using a validated tool for the evaluation process.

\section{Conclusion}

Incorporating technology for campus outreach opportunities is not a new concept, but it does appear to be significant and successful for providing students with information and resources for mental health and wellness topics. At a time when serious college student mental health issues have been increasing and major life stressors have occurred, it is even more important to make sure that students have an awareness of common mental health and wellness issues that affect college students, as well as what resources are available to help students respond to these issues effectively. Utilizing condensed, peer-led educational outreach via video format has the potential to aid in the development of psychiatric nursing students and their understanding of the connection between physical wellness, mental wellness and resources. Creating a culture of service and outreach can be considered valuable pieces to the art of nursing, while enhancing the psychiatric mental health nursing clinical experience.

\section{References}

Adams, D. R., Meyers, S. A., \& Bedias, R. S. (2016). The relationship between financial strain, perceived stress, psychological symptoms, and academic and social integration in undergraduate students. Journal of American College Health, 64(5), 362-370. https://doi.org/10.1080/07448481.2016.1154559

Agyapong, V. I. O., Juhás, M., Ohinmaa, A., Omeje, J., Mrklas, K., Suen, V. Y. M., ... Greenshaw, A. J. (2017). Randomized controlled pilot trial of supportive text messages for patients with depression. BMC Psychiatry, 17. https://doi.org/10.1186/s12888-017-1448-2

Agyapong, V., Shalaby, R., Hrabok, M., Vuong, W., Noble, J. M., Gusnowski, A., ... Greenshaw, A. J. (2021). Mental Health Outreach via Supportive Text Messages during the COVID-19 Pandemic: Improved Mental Health and Reduced Suicidal Ideation after Six Weeks in Subscribers of Text4Hope Compared to a Control Population. International Journal of Environmental Research and Public Health, 18(4), 2157. https://doi.org/10.3390/ijerph18042157

American Psychiatric Nurses Association. (2019). Undergraduate Education Faculty Toolkit. Retrieved from https://www.apna.org/i4a/pages/index.cfm?pageid=6030

Britt, S. L., Mendiola, M. R., Schink, G. H., Tibbetts, R. H., \& Jones, S. H. (2016). Financial Stress, Coping Strategy, and Academic Achievement of College Students. Journal of Financial Counseling and Planning, 27(2), 172-183. https://doi.org/10.1891/1052-3073.27.2.172

Copeland, W. E., McGinnis, E., Bai, Y., Adams, Z., Nardone, H., Devadanam, V., ... Hudziak, J. J. (2021). Impact of COVID-19 Pandemic on College Student Mental Health and Wellness. Journal of the American Academy of Child \& Adolescent Psychiatry, 60(1), 134. https://doi.org/10.1016/j.jaac.2020.08.466 
Eifert, E. K., Hall, M. E., Gropper, S. S., \& Kondor, M. (2017). Health Promotion and Institutions of Higher Education: One University's Experience. American Journal of Health Education, 48(4), $219-221$. https://doi.org/10.1080/19325037.2017.1316691

Fogg, N., Wilson, C., Trinka, M., Campbell, R., Thomson, A., Merritt, L., .... Prior, M. (2020). Transitioning from direct care to virtual clinical experiences during the Covid-19 pandemic. Journal of Professional Nursing, 37(5), 685-691. https://doi.org/10.1016/j.profnurs.2020.09.012

Fruehwirth, J. C., Biswas, S., \& Perreira, K. M. (2021). The Covid-19 pandemic and mental health of first-year college students: Examining the effect of Covid-19 stressors using longitudinal data. PLoS ONE, 16(3), 1-15. https://doi.org/10.1371/journal.pone.0247999

Gusmão, L. L., Ribeiro, A. L., Souza-Silva, M. V. R., Gomes, P. R., Beleigoli, A. M., Cardoso, C. S., ... Marcolino, M. S. (2019). Implementation of a text message intervention to promote behavioural change and weight loss among overweight and obese Brazilian primary care patients. Journal of Telemedicine \& Telecare, 25(8), 476-483. https://doi.org/10.1177/1357633X18782092

How to get more students to seek help for mental health. (2020, January 6). College Marketing group. Retrieved May 5, 2021, from https://collegemarketinggroup.com/blog/how-to-get-more-students-to-seek-help-for-mental-health/

Kim, E. J., Yu, J. H., \& Kim, E. Y. (2020). Pathways linking mental health literacy to professional help-seeking intentions in Korean college students. Journal of Psychiatric \& Mental Health Nursing, 27(4), 393-405. https://doi.org/10.1111/jpm.12593

Leigh, J., Vasilica, C., Dron, R., Gawthorpe, D., Burns, E., Kennedy, S., ... Croughan, C. (2020). Redefining undergraduate nurse teaching during the coronavirus pandemic: Use of digital technologies. Br J Nurs, 29(10). https://doi.org/10.12968/bjon.2020.29.10.566

McKenzie, L. Colleges use technology to help students manage mental health. Inside Higher Ed. Retrieved from https://www.insidehighered.com/news/2018/10/05/colleges-turn-wellness-app-address-student-mental-healt h\#: :text=Colleges\%20Use \%20Technology\%20to\%20Help,replace\%2C\%20in\%2Dperson\%20services

National Center for Health Statistics. (2018). Suicide mortality in the United States, 1999-2017. (Report No. 330). Retrieved from https://www.cdc.gov/nchs/data/databriefs/db330-h.pdf

Reid, K., Armstrong, N., Todd, D., Ballard, L., Szczepaniak, C., \& Tinsley, C. (2021). An examination of mental health, perceived barriers, and outreach recommendations among rural college students. American Journal of Health Education, 52(2), 101-110. https://doi.org/10.1080/19325037.2021.1877220

Sebastian, J., \& Richards, D. (2017). Changing stigmatizing attitudes to mental health via education and contact with embodied conversational agents. Computers in Human Behavior, 73, 479-488. https://doi.org/10.1016/j.chb.2017.03.071

\section{Appendix A}

Objectives for each topic:

1. Provide education to enhance and support the emotional well-being of the campus community.

2. Demonstrate effective health promotion skills using teaching and counseling abilities grounded in supporting motivation and self-efficacy for seeking healthy behaviors

3. Show ability to plan, implement, and evaluate preventive care on primary, secondary, and tertiary levels.

American Psychiatric Nurses Association (2019). 


\section{Appendix B}

Post-Evaluation Questions for Students

\begin{tabular}{|c|c|c|c|}
\hline $\begin{array}{l}\text { Not helpful at } \\
\text { all }\end{array}$ & Not helpful & Neutral & Helpful \\
\hline
\end{tabular}

Did the video

presentation improve

your knowledge on the

topic you presented?

\section{Did the video \\ presentation improve \\ your ability to work \\ effectively in a group?}

\section{Did the video \\ presentation improve \\ your ability to develop a \\ professional \\ presentation?}

\section{Do you feel the video presentation pointed students to campus and other mental health resources?}

What are suggestions for improvement (creating videos, the assignment, etc.)?

What suggestions for improvement do you have to promote the videos?

\section{Copyrights}

Copyright for this article is retained by the author(s), with first publication rights granted to the journal.

This is an open-access article distributed under the terms and conditions of the Creative Commons Attribution license (http://creativecommons.org/licenses/by/4.0/). 